\title{
Severe acute respiratory syndrome coronavirus-2- or pregnancy-related cardiomyopathy, a differential to be considered in the current pandemic: a case report
}

\author{
Rahim Nejadrahim ${ }^{1}$, Sara Khademolhosseini ${ }^{2}$, Hadiseh Kavandi ${ }^{3}$ and Reza Hajizadeh ${ }^{4 *}$
}

\begin{abstract}
Background: There are limited data on cardiovascular complications of coronavirus disease 2019 in pregnancy, and there are only a few case reports on coronavirus disease 2019 related cardiomyopathy in pregnancy. Differentiation between postpartum cardiomyopathy and coronavirus disease 2019 related cardiomyopathy in pregnant women who develop severe acute respiratory syndrome coronavirus-2 infection during peripartum could be challenging. Here, we present a case of possible coronavirus disease 2019 related cardiomyopathy in a pregnant patient, followed by a discussion of potential differential diagnosis.
\end{abstract}

Case presentation: In this case report, we present the case of a young pregnant Iranian woman who developed heart failure with pulmonary edema after cesarean section. She was treated because of low left ventricular ejection fraction and impression of postpartum cardiomyopathy, and her severe dyspnea improved by intravenous furosemide. On day 3, she exhibited no orthopnea or leg edema, but she was complaining of severe and dry cough. Further evaluation showed severe acute respiratory syndrome coronavirus-2 infection.

Conclusions: The possibility of severe acute respiratory syndrome coronavirus- 2 infection should be considered in any pregnant woman who develops cardiomyopathy and pulmonary edema.

Keywords: COVID-19, Cardiomyopathy, Pregnancy

\section{Background}

The novel coronavirus disease 2019 (COVID-19), caused by severe acute respiratory syndrome coronavirus-2 (SARS-CoV-2) has become a global health emergency these days. Currently, more than 17.5 million confirmed cases have been reported worldwide [1]. Although COVID-19 is presenting predominantly with pulmonary manifestations, there have been many reports of multiorgan involvement, including the cardiovascular system [2].

*Correspondence: hajizadh.reza@gmail.com

${ }^{4}$ Department of Cardiology, Urmia University of Medical Sciences, Urmia, Iran

Full list of author information is available at the end of the article
COVID-19 related cardiomyopathy, viral myocarditis, myocardial infarction, and arrhythmia are some of the complications reported in the general adult population [3]. Almost 30\% of patients with confirmed COVID-19 were found to have evidence of myocardial injury and COVID-19 related cardiomyopathy [4, 5]. The diagnosis of postpartum cardiomyopathy without further evaluation for COVID-19 infection could negatively affect outcomes.

\section{Case presentation}

A 38-year-old pregnant Iranian woman without any history of cardiac disease, diabetes mellitus, hypertension, or psychiatric problems, was admitted for cesarean original author(s) and the source, provide a link to the Creative Commons licence, and indicate if changes were made. The images or other third party material in this article are included in the article's Creative Commons licence, unless indicated otherwise in a credit line to the material. If material is not included in the article's Creative Commons licence and your intended use is not permitted by statutory regulation or exceeds the permitted use, you will need to obtain permission directly from the copyright holder. To view a copy of this licence, visit http://creativecommons.org/licenses/by/4.0/. The Creative Commons Public Domain Dedication waiver (http://creativeco mmons.org/publicdomain/zero/1.0/) applies to the data made available in this article, unless otherwise stated in a credit line to the data. 
section because of severe preeclampsia. She did not have any family history of ischemic heart disease or familial cardiomyopathies. She had a bachelor degree in nursery. After successful delivery, she was discharged without any complaints; 12 days after cesarean section, she was admitted again with severe dyspnea and sweating, and her blood oxygen saturation was $80 \%$ on room air. Physical examination showed blood pressure of $120 / 85$, heart rate of 115 beats per minute, respiratory rate of 33 breaths per minute, and audible crackles in the lower half of both lungs (day 1 of second admission). Bedside echocardiography showed left ventricular ejection fraction (LVEF) of $40 \%$ with a normal left ventricular (LV) size (LV end diastolic size $4.9 \mathrm{~cm}$ ) with mild to moderate mitral regurgitation. With the diagnosis of pulmonary edema, intravenous furosemide was started, which improved her dyspnea, and with the diagnosis of postpartum cardiomyopathy, bisoprolol, captopril, and furosemide were administered. On day 3 , she had no orthopnea or leg edema but was complaining of severe and dry cough. She did not have fever, myalgia, chest pain, or gastrointestinal discomfort. She had no significant medical history and no travel history to a foreign country.

Her vital signs indicated blood pressure of $110 / 70 \mathrm{mmHg}$, heart rate of 74 beats per minute, body temperature of $37.2{ }^{\circ} \mathrm{C}$, and respiratory rate of 20 breaths per minute with an oxygen saturation of $94 \%$ on room air.

Apart from tachypnea, her physical examination revealed normal jugular venous pulse, scattered bilateral rales, and no peripheral edema. Heart auscultation was normal without pericardial rub.

Diagnostic laboratory tests revealed elevated lactate dehydrogenase (564 U/L) and CRP (3+), leukopenia (WBC count 3400), erythrocyte sedimentation rate (ESR) $50 \mathrm{~mm} /$ hour, and mildly elevated serum troponin and D-dimer levels. Other laboratory data are presented in Table 1.

A 12-lead electrocardiogram showed negative $\mathrm{T}$ waves in I, AVL, and V5-V6 leads and poor R progression in precordial leads without Q wave and with prolonged QT interval (QTc $500 \mathrm{~ms}$ ) (Fig. 1). Because her tachypnea did not resolve with proper furosemide administration, on day 3, a new chest X-ray was done that was not consistent with pulmonary edema. To evaluate other causes of dyspnea, a chest computed tomography was done, showing peripheral patchy and ground-glass opacities in both lungs concordant with COVID 19 infection. No hilar or mediastinal lymphadenopathy was observed. There was also pleural effusion on both sides (Fig. 2).

A nasopharyngeal swab for severe acute respiratory syndrome coronavirus 2 (SARS-CoV-2) real-time reverse transcription polymerase chain reaction (RT-PCR) was positive. Thus, azithromycin,
Table 1 Laboratory tests of patient on admission

\begin{tabular}{ll}
\hline Laboratory test & Value \\
\hline Blood sugar & 172 \\
Urea & 30 \\
Creatinin & 1.1 \\
Na & 139 \\
K & 3.5 \\
Hemoglobin & 11 \\
Mean corpuscular volume & 88.65 \\
Platelets & 200,000 \\
Prothrombin time & 11.4 \\
Partial thromboplastin time & 31 \\
INR & 0.92 \\
Cholesterol & 134 \\
Triglyceride & 272 \\
High-density lipoprotein & 35 \\
Low-density lipoprotein & 56 \\
SGOT & 21 \\
SGPT & 27 \\
Creatine phosphokinase & 93 \\
Bilirubin (direct) & 0.3 \\
Bilirubin (indirect) & 0.7 \\
\hline
\end{tabular}

INR international normalized ratio, Na sodium, K potassium, SGOT serum glutamic oxaloacetic transaminase, SGPT serum glutamic pyruvic transaminase

lopinavir-ritonavir, subcutaneous interferon $\beta 1$ (Resigen), and intravenous immunoglobulin gamma (IVIG) ( $20 \mathrm{~g} /$ day for 3 days) were added to her medications [6].

On the eighth day of second admission, she again developed severe dyspnea and pulmonary edema, and her blood pressure was $110 / 70$, heart rate 110 beats per minute, respiratory rate 25 breaths per minute, and audible crackles in the lower third of both lungs. Intravenous furosemide $40 \mathrm{mg}$ stat and $6 \mathrm{mg}$ per hour started, which stabilized her condition. Echocardiography was performed again on the 11th day of admission, showing LVEF of $30 \%$, global hypokinesis, LV enlargement (LV end diastolic size $5.8 \mathrm{~cm}$ ), and normal right ventricle (RV) size with reduced RV systolic function. Again, IVIG $20 \mathrm{~g} /$ day was started and continued for 3 days. On the 12th day of admission, the patient's clinical status stabilized and her symptoms disappeared. Chest X-ray showed improvement of lung infection and no evidence of pulmonary edema (Fig. 3). Her heart rate decreased to 70 beats per minute with a respiratory rate of 14 breaths per minute. Oxygen saturation on room air was $95 \%$, and her body temperature was $37.0^{\circ} \mathrm{C}$ (by mouth).

Her second RT-PCR was negative, and she was discharged with a prescription of carvedilol, enalapril, furosemide, digoxin, and bromocriptine. 


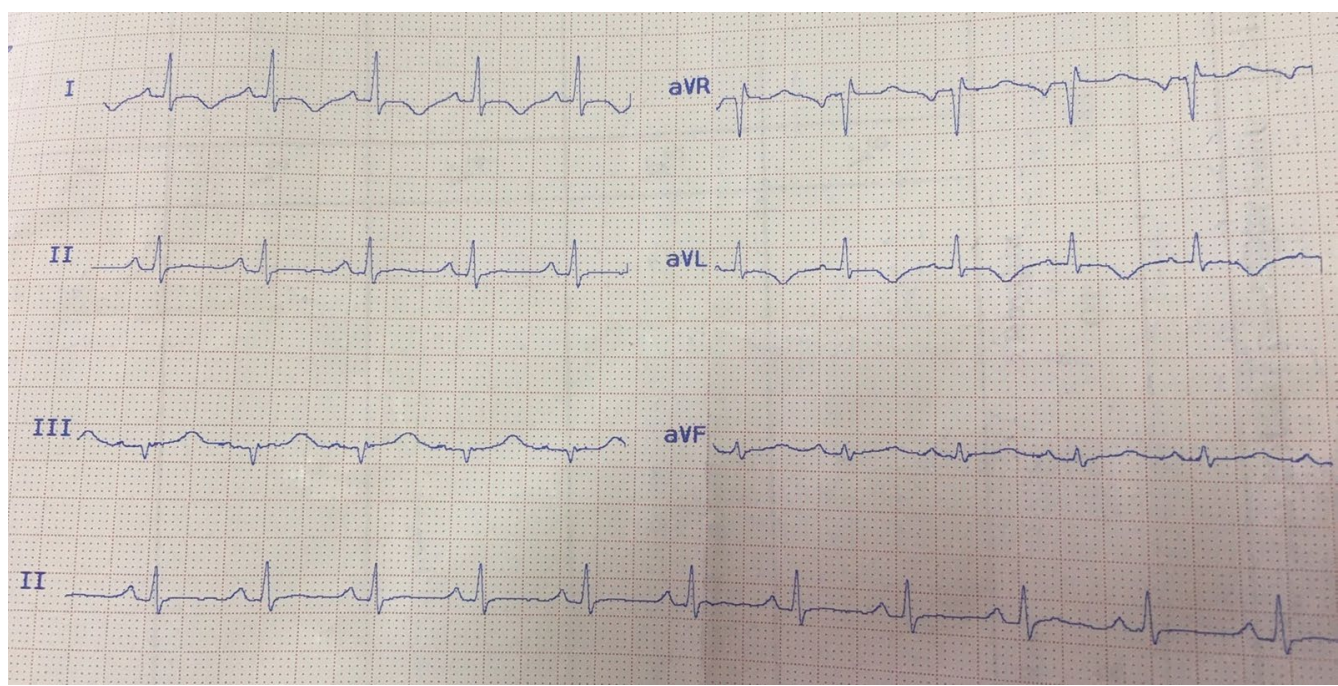

Fig. 1 Negative T waves in lateral leads and long QTC

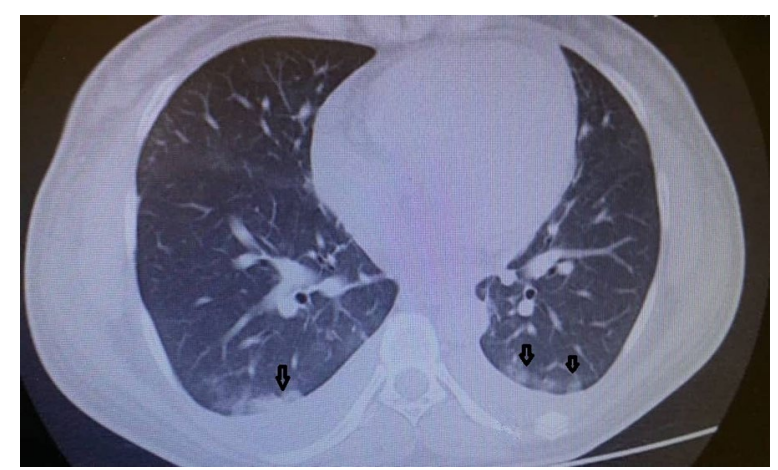

Fig. 2 Chest computed tomography showing peripheral patchy and ground-glass opacities (arrows) in both lungs and pleural effusion

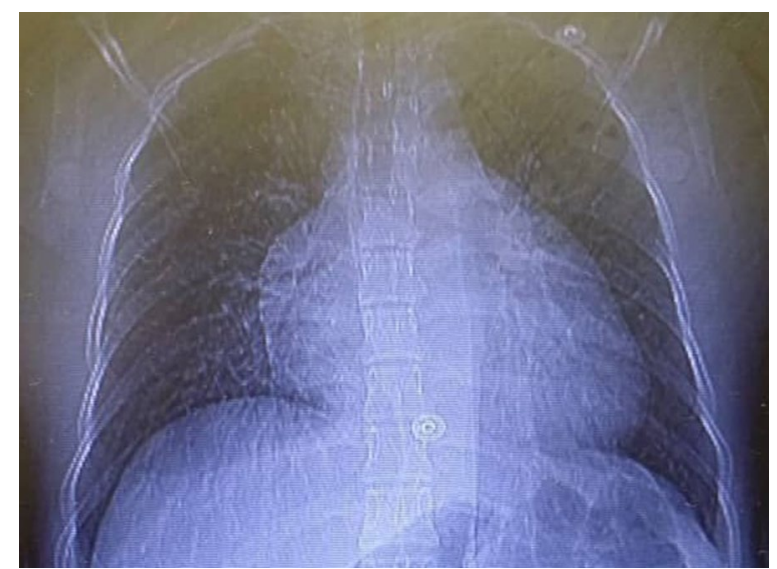

Fig. 3. Chest $X$-ray showing improved COVID-19 infection and no pulmonary edema with cardiomegaly on 12th day of admission
Thirty days after discharge, she was admitted to the clinic as an outpatient. At this visit, her vital signs were stable, she had mild exertional dyspnea, and her $\mathrm{O}_{2}$ saturation was $96 \%$ on room air. She was excited about starting her job as a nurse, following with necessary COVID 19 prevention guidelines.

\section{Discussion}

Cardiovascular complications of COVID-19 are important in the prognosis and survival of patients. Guo et al. studied 187 COVID-19 patients and found 27.8\% with evidence of myocardial injury [4]. A study of the Washington State COVID-19 cohort revealed cardiomyopathy in $33 \%$ of nonpregnant patients in the intensive care unit [5]. There are limited data on COVID-19 in pregnancy. Juusela and colleagues reported two cases of COVID-19 related cardiomyopathy in pregnant women [7].

The mechanism by which SARS-CoV-2 causes myocardial injury is not fully understood. Studies on the role of ACE-2 receptors in viral life cycle and the effects of ACE-2 disruption show that the interaction between ACE-2 and SARS virus might be causing myocardial inflammation and injury [8]. Additionally, the downregulation of ACE-2 hinders the cardioprotective effects of angiotensin and subsequently increases tumor necrosis factor alpha (TNF $\alpha$ ) production, which may be contributing to myocardial damage [9]. Exaggerated cytokine response is also a potential mediator of cardiomyocyte damage [4].

Here, our case was a young female with no remarkable risk factors for cardiomyopathy. The main cause of her disease could be undiagnosed postpartum 
cardiomyopathy, aggravated by COVID-19 cardiomyopathy. According to Pierce-Williams et al. [10], who studied severe and critical COVID-19 in a cohort of hospitalized pregnant patients in the United States, only $17 \%$ of patients had preexisting cardiac disease. Being of childbearing age, in addition to a lack of other cardiac risk factors, makes the undiagnosed heart failure a less likely differential diagnosis.

Pregnancy-associated cardiomyopathy is a major differential diagnosis. It is defined as the development of heart failure toward the end of pregnancy or closely after delivery with the absence of another identifiable etiology for heart failure [11]. The exact mechanism is still unclear and probably multifactorial. Angiogenic imbalance, as evidenced by prolactin levels, and high levels of inflammatory cytokines such as TNF $\alpha$ and interleukin-6 (IL-6) are potential contributors [12]. High levels of inflammatory markers, especially IL-6, might be a clue to finding a possible common pathophysiology for pregnancy-associated cardiomyopathy and COVID-19 related cardiomyopathy. IL-6 also plays an important role in COVID-19 pathophysiology. Zeng et al. reviewed inflammatory markers in over 3900 COVID-19 patients and found that survivors had a lower level of IL-6 compared with nonsurvivors [13]. It is possible that common pathways such as IL-6 could trigger and aggravate dilated cardiomyopathy in pregnant women who develop COVID-19 in peripartum period, and COVID-19 prevention might be more important in this period. Although rapid progression of heart failure in postpartum dilated cardiomyopathy is not uncommon, it is important to observe the severity of dilated cardiomyopathy in peripartum COVID19-positive patients to better understand its nature $[14,15]$.

Further studies are needed to investigate whether pregnancy affects the chance of developing COVID19-related cardiomyopathy compared with the general population. Also, there is a lot to learn about how pregnancy and COVID-19-related cardiomyopathy affect each other. Studying the role of inflammatory cytokines such as IL-6 in the process of myocardial injury might shed light on the pathophysiology underlying pregnancy and COVID-19-related cardiomyopathy. A dedicated subgroup analysis of myocardial injury in ongoing trials on anti-IL-6 receptor antibodies, such as tocilizomab, for COVID-19 is recommended.

We suggest routine echocardiographic evaluation of pregnant patients with COVID-19 as they are at a higher risk of cardiovascular complications due to the role of inflammatory markers.

\section{Conclusion}

It is important to test for severe acute respiratory syndrome coronavirus-2 infection in pregnant women with cardiomyopathy and primary diagnosis of postpartum cardiomyopathy during the COVID-19 pandemic.

\section{Abbreviations \\ SARS: Severe acute respiratory syndrome; LVEF: Left ventricular ejection fraction; CRP: C-reactive protein; WBC: White blood cells; IVIG: Intravenous immunoglobulin; RV: Right ventricle; ICU: Intensive care unit; ACE: Angioten- sin-converting enzyme; IL-6: Interleukin 6.}

\section{Acknowledgements \\ None.}

Authors' contributions

Conceptualization: $\mathrm{RN}, \mathrm{RH}$; writing (original draft preparation): $\mathrm{SK}$, HK; writing (review and editing): $\mathrm{RH}$; resources: $\mathrm{RN}$; supervision: $\mathrm{RN}, \mathrm{RH}$. All authors read and approved the final manuscript.

Funding

This study was supported by the Urmia University of Medical Sciences.

Availability of data and materials

All data and material collected during this study are available from the corresponding author upon reasonable request.

\section{Declarations}

Ethics approval and consent to participate

Written informed consent was obtained from the patient for publication of this case report and any accompanying images. A copy of the written consent is available for review by the Editor-in-Chief of this journal. This study was approved by the medical ethics committee of the Urmia University of Medical Sciences with registration number of IR.UMSU.REC.1399.214

\section{Consent to participate}

Informed consent was obtained from participant.

\section{Consent for publication}

Written informed consent was obtained from the patient for publication of this case report and any accompanying images. A copy of the written consent is available for review by the Editor-in-Chief of this journal

\section{Competing interests}

The authors declare that they have no competing interests.

\section{Author details}

${ }^{1}$ Department of Infectious Diseases, Urmia University of Medical Sciences, Urmia, Iran. ${ }^{2}$ School of Medicine, Shiraz University of Medical Sciences, Shiraz, Iran. ${ }^{3}$ Connective Tissue Diseases Research Center, Tabriz University of Medical Sciences, Tabriz, Iran. ${ }^{4}$ Department of Cardiology, Urmia University of Medical Sciences, Urmia, Iran.

Received: 27 September 2020 Accepted: 22 February 2021 Published online: 19 March 2021

References

1. Tanno LK, Casale T, Demoly P. Coronavirus disease (COVID)-19: World Health Organization definitions and coding to support the allergy community and health professionals. J Allergy Clin Immunol. 2020;8:2144-8.

2. Babapoor-Farrokhran S, Gill D, Walker J, Rasekhi RT, Bozorgnia B, Amanullah A. Myocardial injury and COVID-19: possible mechanisms. Life Sci. 2020;253:117723 
3. Long B, Brady WJ, Koyfman A, Gottlieb M. Cardiovascular complications in COVID-19. Am J Emerg Med. 2020;38:1504-7.

4. Guo T, Fan Y, Chen M, Wu X, Zhang L, He T, et al. Cardiovascular implications of fatal outcomes of patients with coronavirus disease 2019 (COVID19). JAMA Cardiol. 2020;5:811.

5. Arentz M, Yim E, Klaff L, Lokhandwala S, Riedo FX, Chong M, et al. Characteristics and outcomes of 21 critically ill patients with COVID-19 in Washington State. JAMA. 2020;323(16):1612-4.

6. Bose S, Adapa S, Aeddula NR, Roy S, Nandikanti D, Vupadhyayula PM, et al. Medical management of COVID-19: evidence and experience. J Clin Med Res. 2020;12(6):329-43 (Epub 06/04. eng)

7. Juusela A, Nazir M, Gimovsky M. Two cases of COVID-19 related cardiomyopathy in pregnancy. Am J Obstet Gynecol. 2020;2:100113.

8. Oudit G, Kassiri Z, Jiang C, Liu P, Poutanen S, Penninger J, et al. SARS-coronavirus modulation of myocardial ACE2 expression and inflammation in patients with SARS. Eur J Clin Invest. 2009;39(7):618-25.

9. Crackower MA, Sarao R, Oudit GY, Yagil C, Kozieradzki I, Scanga SE, et al. Angiotensin-converting enzyme 2 is an essential regulator of heart function. Nature. 2002;417(6891):822-8.

10. Pierce-Williams RAM, Burd J, Felder L, Khoury R, Bernstein PS, Avila K, et al. Clinical course of severe and critical COVID-19 in hospitalized pregnancies: a US cohort study. Am J Obstet Gynecol. 2020;2:100134.

11. Bauersachs J, König T, van der Meer P, Petrie MC, Hilfiker-Kleiner D, Mbakwem $\mathrm{A}$, et al. Pathophysiology, diagnosis and management of peripartum cardiomyopathy: a position statement from the Heart Failure Association of the European Society of Cardiology Study Group on peripartum cardiomyopathy. Eur J Heart Fail. 2019;21(7):827-43.

12. Sliwa K, Förster O, Libhaber E, Fett JD, Sundstrom JB, Hilfiker-Kleiner D, et al. Peripartum cardiomyopathy: inflammatory markers as predictors of outcome in 100 prospectively studied patients. Eur Heart J. 2006;27(4):441-6.

13. Zeng F, Guo Y, Yin M, Chen X, Deng G. Association of inflammatory markers with the severity of COVID-19. medRxiv. 2020.

14 Pearson GD, Veille JC, Rahimtoola S, Hsia J, Oakley CM, Hosenpud JD, et al. Peripartum cardiomyopathy: National Heart, Lung, and Blood Institute and Office of Rare Diseases (National Institutes of Health) workshop recommendations and review. JAMA. 2000;283(9):1183-8 (Epub 2000/03/07. eng)

15. Shah T, Ather S, Bavishi C, Bambhroliya A, Ma T, Bozkurt B. Peripartum cardiomyopathy: a contemporary review. Methodist Debakey Cardiovasc J. 2013;9(1):38-43.

\section{Publisher's Note}

Springer Nature remains neutral with regard to jurisdictional claims in published maps and institutional affiliations.
Ready to submit your research? Choose BMC and benefit from:

- fast, convenient online submission

- thorough peer review by experienced researchers in your field

- rapid publication on acceptance

- support for research data, including large and complex data types

- gold Open Access which fosters wider collaboration and increased citations

- maximum visibility for your research: over 100M website views per year

At BMC, research is always in progress.

Learn more biomedcentral.com/submissions 